\title{
A ação do óleo de pequi (Caryocar brasiliense) no processo cicatricial de lesões cutâneas em ratos.
}

\author{
BEZERRA, N.K.M.S. ${ }^{1 *}$; BARROS, T.L.'; COELHO, N.P.M.F. ${ }^{2}$ \\ ${ }^{1}$ Faculdade Integral Diferencial - FACID, Avenida Rio Poty, 2381, Horto Florestal, CEP: 64049-410, Teresina- PI, \\ Brasil. 2Universidade Estadual do Piauí-UESPI e Faculdade Integral Diferencial - FACID, Rua Miosótis, 303/2202, \\ CEP: 64049-536, Teresina - PI Brasil. *Autor para correspondência: namasil@hotmail.com
}

\begin{abstract}
RESUMO: O objetivo deste estudo foi analisar o efeito do óleo de pequi no processo cicatricial de lesões cutâneas em ratos. A pesquisa foi iniciada após a provação da CEUA- FACID sob o $\mathrm{n}^{\circ}$ de protocolo 005/12 e obedeceu aos princípios éticos da experimentação animal de acordo com a Lei Federal no 11.794/2008. Foram utilizados 20 ratos machos, Wistar (Rattus norvegicus), peso corpóreo de $300-350 \mathrm{~g}$, divididos aleatoriamente em dois grupos iguais: GIcontrole (C); Gll- tratado com óleo de pequi (T). Cada grupo foi dividido em dois subgrupos, de cinco animais cada, conforme os tempos experimentais estudados de 7(A) e 14(B) dias. Após anestesia e antissepsia foi produzida cirurgicamente ferida circular de $2,5 \mathrm{~cm}$ de diâmetro na região dorso lombar do animal. Os animais do Grupo II foram tratados com aplicação tópica diária de $1 \mathrm{ml}$ do óleo de pequi, respeitando os tempos experimentais descritos. Concomitante à mensuração da área da lesão, os ratos foram eutanasiados para realização do processamento histológico e análise do percentual de regressão das lesões. No grupo GII nos diferentes tempos experimentais de 7 e 14 dias foi observado maior percentual de regressão das lesões em relação ao $\mathrm{GI}(p<0,05)$. A partir da análise histológica foi possível detectar que no Gll houve menor número de células inflamatórias e maior número de fibroblastos em relação ao GI nos diferentes tempos experimentais $(p<0,001)$. Conclui-se que o uso do óleo de pequi apresentou influência positiva no processo de reparo de lesões cutâneas em ratos, por promover maior velocidade do reparo tecidual, fato evidenciado pelo fechamento mais rápido das feridas e observação de características inflamatórias reduzidas no grupo tratado em relação ao grupo controle, sugerindo que a inflamação pode já ter regredido no grupo tratado.
\end{abstract}

Palavras-chave: Caryocar brasiliense. Feridas. Inflamação. Cicatrização.

\begin{abstract}
The effect of the Pequi oil (Caryocar brasiliense) in the healing of skin lesions in mice. The aim of this study was to analyze the effect of pequi oil in the healing process of skin lesions in rats. The research was initiated after the ordeal of CEUA- FACID with protocol No. $005 / 12$ and following the ethical principles of animal experimentation according to the Federal Law No. 11,794 / 2008. 20 Wistar rats were used (Rattus norvegicus), with body weight ranging from $300-350 \mathrm{~g}$. They were randomly divided into two groups: GI control (C) and GII treated with pequi oil $(\mathrm{T})$. Each group was divided into two subgroups of five animals each, according to the experimental study of 7 days (A) and 14 (B) days. After anesthesia and antisepsis, a circular wound of $2.5 \mathrm{~cm}$ of diameter was surgically inflicted in the lumbar dorsal region of the animal. The animals in Group II were treated with daily topical application of $1 \mathrm{ml}$ of pequi oil, respecting the described experimental times. Concomitantly with the measurement of the injury area, the rats were euthanized so that a histological processing and a regression analysis of the percentage of injuries could be performed. In GII, at different experimental times of 7 and 14 days, there were a higher percentage of lesions regression compared to $\mathrm{GI}(p<0.05)$. From the histological examination it was possible to detect that, at GII, there were a lower number of inflammatory cells and increased number of fibroblasts compared to IM at different time of the trial $(P<0.001)$. It is concluded that the use of pequi oil presented positive influence on the healing process of skin lesions in rats by promoting quicker tissue repair, as indicated by the faster closure of the wounds and the observation of reduced inflammatory characteristics in the group treated compared to the control group, suggesting that the inflammation could have already receded in the treated group.
\end{abstract}

Keywords: Caryocar brasiliense. Wounds. Inflammation. Healing.

Recebido para publicação em 26/06/2014

Aceito para publicação em 20/02/2015

10.1590/1983-084X/14_061

Rev. Bras. PI. Med., Campinas, v.17, n.4, supl. II, p.875-880, 2015. 


\section{INTRODUÇÃO}

A inflamação é uma reação local dos tecidos conjuntivos como resposta a um agente agressor. É um mecanismo de defesa no qual o organismo se vale para tentar conter ou isolar uma lesão, destruir possíveis invasores, inativar toxinas e preparar os tecidos para cicatrização e reparação. Como resultado deste processo, sinais clínicos são evidenciados como dor, calor, rubor, edema e perda da função (Robbins \& Cotran, 2005).

Lima et al. (2007) relataram que quando o organismo desenvolve a resposta inflamatória, desta participam diferentes tipos de células, como neutrófilos, macrófagos, mastócitos, linfócitos, plaquetas, células endoteliais e fibroblastos.

Quando as células, tecidos e órgãos sofrem uma agressão, tanto do meio externo (exógeno), como do meio interno (endógeno) eles tendem a uma recomposição para voltar ao estado de homeostase, que seria uma situação de equilíbrio do organismo, refletindo no desempenho das funções fisiológicas. A resposta a essas agressões se dá por meio do processo inflamatório que é um dos mais eficientes mecanismos de defesa (Reis \& Teixeira, 2004).

Após muitas controvérsias, o uso de plantas medicinais começa a ter apoio científico em todos os recantos do planeta. O Brasil e outros países, com apoio da Organização Mundial de Saúde, estão começando a resgatar a medicina popular, em que o estudo das plantas medicinais ressurge. Muitas delas têm uso milenar, posto que existe citação de várias em papiros do antigo Egito. Atualmente, encontram-se facilmente em revistas indexadas, pesquisas relatando o uso, importância e efeitos destas plantas em diversos tratamentos (Maia-Filho et al., 2011).

O Bioma Cerrado é a segunda maior formação vegetal brasileira depois da Amazônia e também é a savana tropical mais rica do mundo em biodiversidade, concentrando um terço da biodiversidade nacional e $5 \%$ da flora e da fauna mundial. Dentre as fruteiras do Cerrado brasileiro, com forte potencial para a exploração sustentada, encontra-se o pequi (Caryocar brasiliense), estas frutas são bastante ricas do ponto de vista nutricional e funcional, apresentando propriedades sensoriais, como cor, aroma e sabor diferenciados e muito agradáveis. São consumidas tradicionalmente in natura ou, preferencialmente cozido, acompanhado de arroz elou de carne (Faleiro et al., 2008). No entanto, poucos estudos etnobotânicos e farmacológicos têm sido realizados nessa região.

O óleo de Caryocar coriaceum (pequi), rico em ácidos graxos insaturados, tem sido utilizado na alimentação e indústria cosmética, sendo indicado na medicina popular por seus efeitos anti- inflamatório e cicatrizante, no tratamento de doenças respiratórias, úlceras gástricas, dores musculares e reumáticas (Matos, 2007). Entretanto, esses efeitos ainda necessitam de validação científica.

Azevedo-Meleiro \& Rodriguez-Amaya (2004) identificaram carotenóides no pequi Caryocar brasiliense. Estes metabólitos conferem proteção à pele impedindo a lipoperoxidação, evitando desta maneira a formação de radicais livres e consequentemente retardando envelhecimento cutâneo. Também foram demonstradas as atividades leishmanicida e antimicrobiana do extrato das folhas de pequi (Paula Junior et al., 2006).

Diante do exposto, o presente estudo teve por objetivo analisar o efeito do óleo de pequi no processo cicatricial de lesões cutâneas em ratos, tratados com uso tópico do óleo mediante análise macroscópica e histopatológica do processo cicatricial até o $14^{\circ}$ dia de pós-operatório.

\section{MATERIAL E MÉTODOS}

O protocolo experimental deste trabalho foi aprovado pela Comissão de Ética no Uso de Animais (CEUA) da FACID sob o número 005/2012.

Foram utilizados 20 ratos machos, provenientes do biotério da Faculdade Integral Diferencial-FACID, Wistar (Rattus norvegicus), peso corpóreo de $300-350 \mathrm{~g}$, acondicionados em gaiolas de plástico, em condições de temperatura de 22-25 ${ }^{\circ} \mathrm{C}$ e ciclo claro/escuro de $12 / 12 \mathrm{~h}$. Os animais foram submetidos às condições de manejo idênticas, alimentados com ração e água à vontade, divididos aleatoriamente em dois grupos iguais: GI- controle (C); GII- tratado com óleo de pequi (T). Cada grupo foi dividido em dois subgrupos, de cinco animais cada, conforme os tempos experimentais estudados de 7(A) e 14(B) dias.

O óleo de pequi (Caryocar brasiliense) foi adquirido comercialmente na Central de Abastecimento da cidade de Teresina-PI em junho de 2013 na forma caseira.

Para a realização das lesões cutâneas, os animais receberam dose de $0,2 \mathrm{ml}$ de atropina como medicação pré-anestésica por via subcutânea. Os animais foram pesados e de acordo com seu peso, anestesiados através de dissociação de cloridrato de xilazina ( $2 \%$ ) e cloridrato de quetamina $(10 \%)$ na dose de 0,1 ml para cada $100 \mathrm{~g}$ de peso corpóreo, administrada por via intramuscular. Após anestesia, foram feitas tricotomia e antissepsia com álcool iodado a $2 \%$ no local cirúrgico (Massone, 2003).

Após a contenção dos animais em decúbito ventral sobre uma prancha de madeira, realizou-se a tricotomia da região dorsolombar e demarcação da área da ferida, com auxílio de um marcador vazado

Rev. Bras. PI. Med., Campinas, v.17, n.4, supl. II, p.875-880, 2015. 
circular de $2,5 \mathrm{~cm}$ de diâmetro. A área da pele demarcada foi então incidida com lâmina de bisturi e divulsionada da tela subcutânea com tesoura romba e pinça de dissecção.

Foi administrado $1 \mathrm{ml}$ do óleo de pequi sobre a lesão cirúrgica de cada animal tratado, obedecendo os tempos experimentais de 7 e 14 dias, todos os dias até eutanásia dos animais. $O$ grupo controle não recebeu nenhum tratamento.

Concomitante à mensuração da área da lesão, os ratos foram eutanasiados com indução excessiva da anestesia em dose letal por via intraperitoneal. Incisões abrangendo a região da lesão cutânea em toda sua extensão e profundidade juntamente com a pele íntegra ao redor foram realizadas com lâmina de bisturi ficando exposta a fáscia muscular em cada animal. Os fragmentos foram fixados em formol a $10 \%$ para posterior análise histológica.

Para análise macroscópica do percentual de regressão da lesão foi obtida a imagem da ferida por uma câmera digital (Sony Lens), resolução de 14,1 Mpixels, fixada em tripé, mantida a uma distância constante de $30 \mathrm{~cm}$ da lesão cirúrgica e utilizado o software Image J, onde foi delimitado a periferia da lesão e o cálculo da área no pós-operatório imediato e nos diferentes tempos experimentais. O grau de contração expresso em percentual foi mensurado pela fórmula: Área da lesão inicial - área da lesão final / Área da lesão inicial x 100.

Após coloração das lâminas com hematoxilina-eosina (H.E.) foi realizada a contagem de células inflamatórias e fibroblastos para verificação quantitativa da análise histopatológica. Os cortes histológicos foram analisados utilizando o microscópio TCM 400 Labomed, sob a magnificação de 40X, acoplado a uma câmera fotográfica NAO.30, utilizando o programa Pixel Pro, foram tiradas 3 fotos de cada lâmina para obtenção da média das células inflamatórias e fibroblastos.

Após a aquisição das imagens das lâminas coradas com H.E. foi realizada a contagem das células utilizando-se o software ImageJ, a região analisada foi escolhida de forma aleatória, os núcleos presentes foram individualmente marcados pela ferramenta de contagem manual do programa, sendo consideradas as células que estivessem no interior da área delimitada.

Os resultados encontrados foram expressos em média \pm desvio padrão e submetidos à análise de variância e ao teste de Tukey, considerando-se significativo os valores com intervalo de confiança igual a $95 \%$ e $p<0,05$. As análises foram efetuadas utilizando o programa GraphPad Prisma 5.0.

\section{RESULTADOS E DISCUSSÃO}

No grupo tratado com óleo de pequi nos diferentes tempos experimentais foi observado maior percentual de regressão das lesões em relação ao grupo controle $(p<0,05)$ como mostra a Figura 1. Ocorreu diminuição da área das feridas ao longo do tempo e no décimo quarto dia pós-operatório a área encontrada apresentava médias de $0,775 \mathrm{~cm}^{2}$ e $0,424 \mathrm{~cm}^{2}$, para os grupos controle e tratado com óleo de pequi, respectivamente. No $7^{\circ}$ dia a média do percentual de regressão foi de $39,3 \%$ no grupo C e $52,6 \%$ no $T$, resultados semelhantes ocorreram no $14^{\circ}$ dia com $71,2 \%$ (C) e $84,1 \%$ (T). Percebeuse, então que as feridas do grupo $\mathrm{C}$ permaneceram

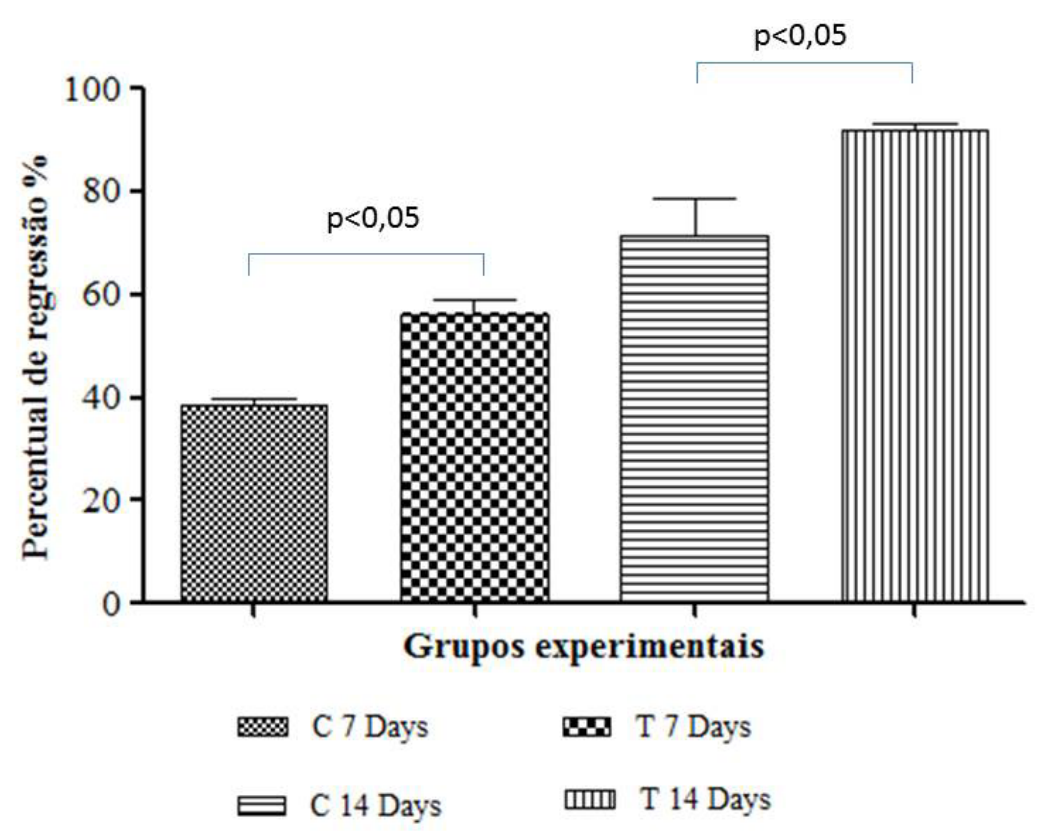

FIGURA 1. Percentual de regressão das lesões cirúrgicas dos grupos controle $(C)$ e tratado $(T)$ com óleo de pequi. 
maiores que as do grupo $\mathrm{T}$.

Da mesma forma Coelho et al. (2013) constataram que após aplicação tópica da emulsão de óleo-em-água de Cenostigma macrophyllum Tul (Caneleiro) em feridas de pele induzidas experimentalmente em ratos com diabetes mellitus houve redução do tamanho da ferida em espécimes dos grupos tratados nos dias 7 e 14 após o ferimento. Batista et al. (2010) ao usarem um creme a base do óleo de pequi encontraram resultados similares em relação ao aumento do percentual de regressão das lesões no grupo tratado.

A Caryocar brasiliense (pequi) é uma árvore originária do Brasil de onde é extraído óleo de interesse cosmético. Na composição do óleo de pequi verifica-se a presença da vitamina $\mathrm{A}$ e de diversos ácidos graxos, tendo como destaque 0 oléico $(50,2 \%)$ e o palmítico (44,3\%), e em menores quantidades os ácidos graxos mirístico, palmitoléico, esteárico, linoléico e linolénico (Croda do Brasil, 2002).

Os ácidos graxos são compostos que contêm uma longa cadeia hidrocarbonada e grupamento carboxila terminal, apresentando três funções principais: são componentes estruturais das membranas biológicas; fazem o papel de precursores de mensagens intracelulares e, quando oxidados, geram energia - ATP (trifosfato de adenosina). Existem diversos estudos que demonstram o efeito benéfico da aplicação tópica de ácidos graxos no tratamento de feridas. São substâncias de baixo custo e amplamente utilizadas como agentes cicatrizantes pela cultura popular de diversos países, apresentando ainda a propriedade de servir de barreira protetora contra os microorganismos, evitando a desidratação tecidual além de importante caráter imunomodulador (Hatanaka \& Curi, 2007).

O produto dos ácidos graxos atuam em diversas etapas do processo inflamatório como contração vascular, quimiotaxia, adesão, migração transendotelial, ativação e morte celular (Cardoso et al., 2004).

$\mathrm{Na}$ avaliação histológica verificou-se resultado significativo nos diferentes tempos experimentais no que diz respeito ao processo inflamatório, no sétimo dia foi observado intenso infiltrado inflamatório no grupo controle, em contrapartida o grupo tratado com óleo de pequi apresentava moderada quantidade de células inflamatórias, além de vasos neoformados e acentuada quantidade de fibroblastos (Figura 2). Aos 14 dias de tratamento o grupo controle apresentava moderada quantidade de células inflamatórias e discreta quantidade de vasos neoformados e fibroblastos. No mesmo período, as feridas dos animais do grupo tratado com óleo de pequi apresentavam-se reparadas em relação ao grupo controle, visto que nesse período foram percebidos achados histológicos característicos da etapa final do processo de cicatrização, tais como acentuada quantidade de fibroblastos e fibras colágenas (Figura 3), sugerindo que a inflamação pode já ter regredido no grupo tratado contribuindo para o avanço do processo de reparo tecidual.

Martins et al. (2011) ao estudarem a fração lipídica do Ovis aries associado ao ultrassom terapêutico (UST) pulsado em modelo de tendinite induzida em ratos encontraram resultados semelhantes aos da presente pesquisa em relação ao avanço do processo de reparo no grupo tratado, relataram que a terapia com UST e Ovis aries apresentou resultado significativo no período de sete dias no que diz respeito ao processo inflamatório. Aos 14 dias de tratamento, observaram maior presença de fibroblastos no grupo UST + oil free e UST + Ovis aries, com tecido colágeno mais organizado, sugerindo que os ácidos graxos, presentes na fração lipídica do Ovis aries, podem ser usados como agentes anti-inflamatórios durante a primeira fase do processo de cicatrização, contribuindo ainda de maneira eficaz na aceleração
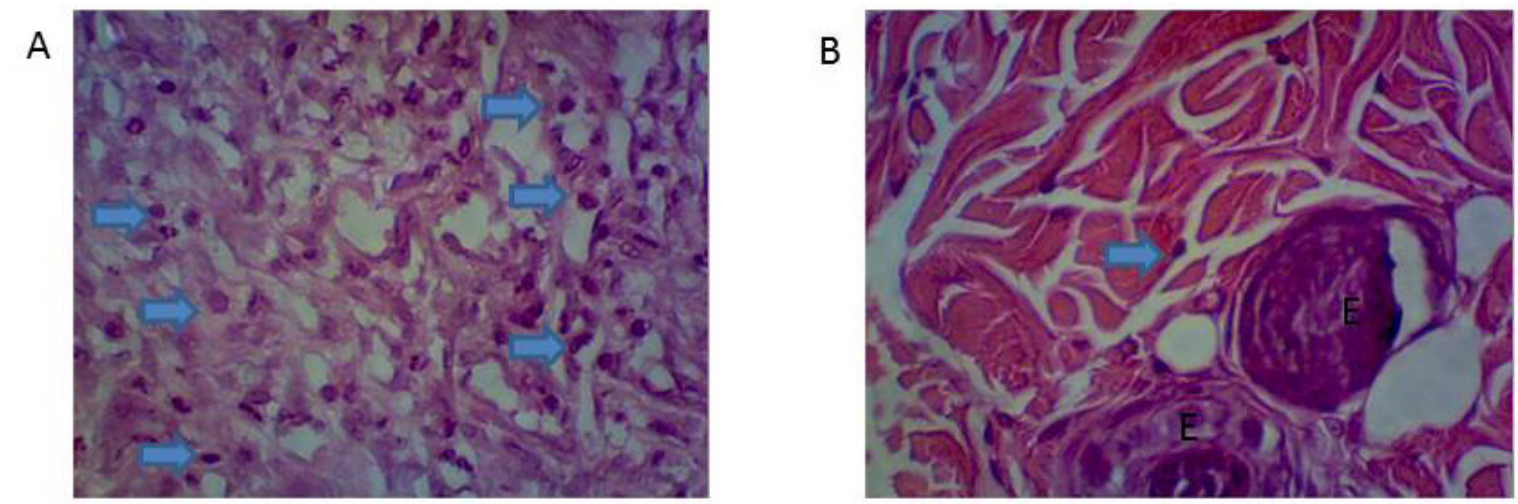

FIGURA 2. Aspecto histológico das feridas cutâneas ao $7^{\circ}$ dia de evolução pós-cirúrgica do grupo controle (A) e tratado (B). Hematoxilina e Eosina. Aumento 40x. Setas (células inflamatórias), E (vasos neoformados). 


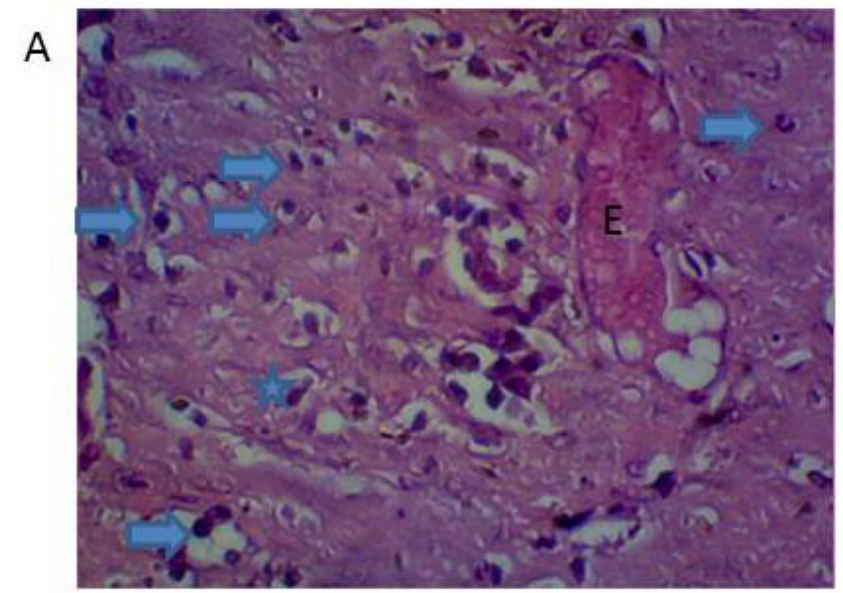

B

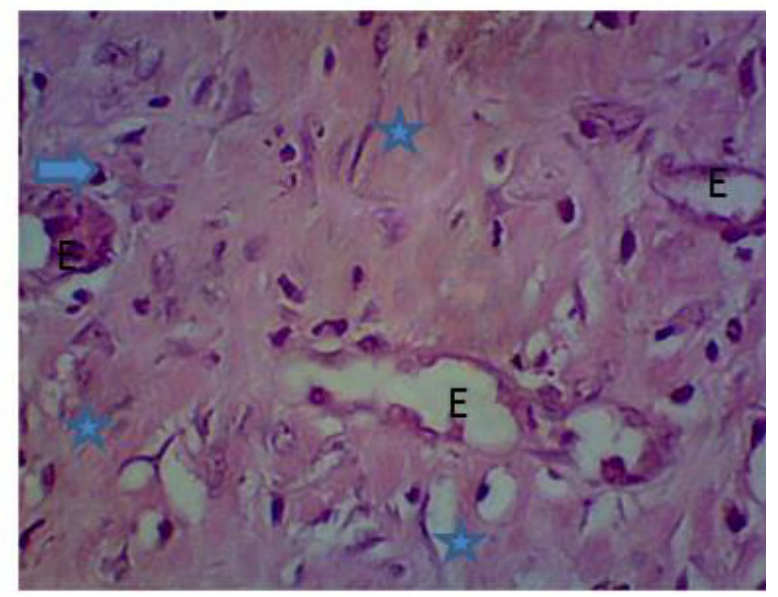

FIGURA 3. Aspecto histológico das feridas cutâneas ao $14^{\circ}$ dia de evolução pós-cirúrgica do grupo controle (A) e tratado (B). Hematoxilina e Eosina. Aumento 40x. Setas (células inflamatórias), E (vasos neoformados), Estrelas (fibroblastos).

do processo de reparação tecidual.

O processo inflamatório promove a exsudação de células leucocitárias que fagocitam e destroem agentes lesivos, restos tissulares e tecido necrótico, sendo portando a inflamação necessária para a boa resposta da reparação tecidual (Mandelbaum et al., 2003). Entretanto, reação inflamatória intensa pode prejudicar o processo de reparo por promover edema, quantidade excessiva de exsudato, os quais favorecem deiscência, crescimento bacteriano e, consequentemente, a inibição da proliferação de fibroblastos e da deposição de colágeno (Cotran et al., 2009).

A angiogênese é etapa fundamental do processo de cicatrização, na qual novos vasos sanguíneos são formados a partir de vasos

A

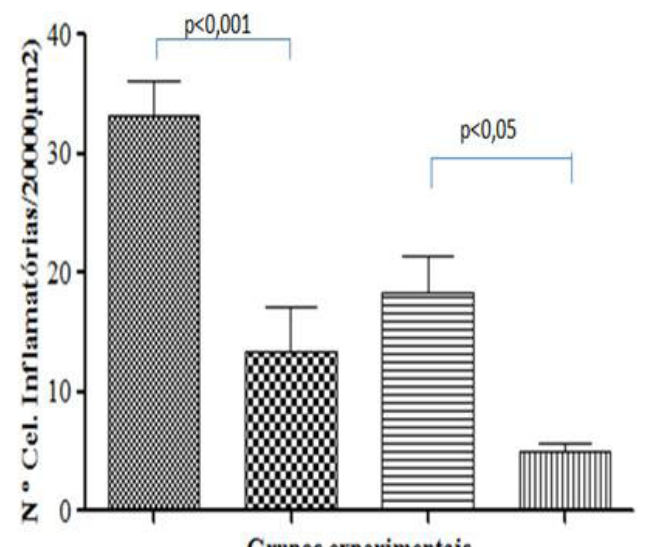

Grupos experimentais preexistentes. Os novos vasos participam da formação do tecido de granulação provisório e supre de nutrientes e de oxigênio o tecido em crescimento. Durante o processo cicatricial, a formação de novos vasos sanguíneos torna-se necessária para a formação do novo tecido de granulação (Mendonca \& Coutinho-Netto, 2009). Esse fato foi bem evidenciado no grupo tratado já no sétimo dia pós-operatório, contribuindo de forma benéfica para aceleração do processo de reparo nas lesões cutâneas dos ratos tratados.

A partir da análise histológica foi possível detectar que no grupo tratado houve menor número de células inflamatórias e maior número de fibroblastos em relação ao grupo controle nos diferentes tempos experimentais como mostra a (Figura 4).
B

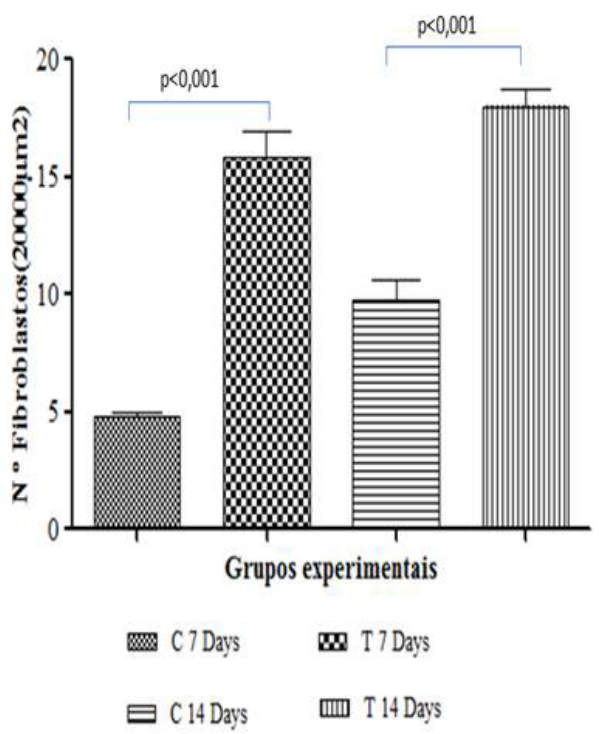

FIGURA 4. Número de células inflamatórias (A) e fibroblastos (B) das lesões cirúrgicas dos grupos controle (C) e tratados $(T)$ com óleo de pequi. 
Um dado importante refere-se à intensidade da inflamação que foi discreta no exame histológico das feridas nos animais do grupo tratado com óleo de pequi, fato também observado por Lima et al. (2007) ao relatarem que o óleo da polpa do pequi apresenta quantidades expressivas de compostos fenólicos.

Compostos fenólicos são utilizados para elevar a eficácia do processo de cicatrização em feridas e úlceras; agindo como antioxidantes, combatem os radicais livres, possuem atividade antimicrobiana e moduladora do sistema imune e apresentam ação anti-inflamatória (Vieira et al., 2008).

Os carotenoides presentes no pequi possuem importantes funções biológicas no ser humano, atuando na prevenção de alguns tipos de câncer, na inibição das mucosas contra úlceras gástricas, na capacidade de prevenir a fotossensibilização em certas doenças de pele, no aumento da resposta imunológica a determinados tipos de infecção e nas propriedades antienvelhecimento (Lima, 2006).

A análise do processo de cicatrização sob os pontos de vista macroscópico e histológico permitiu concluir que o uso do óleo de pequi tem papel benéfico frente ao reparo tecidual, pois promoveu maior velocidade do reparo, fato evidenciado pelo fechamento mais rápido das feridas e observação de características inflamatórias reduzidas no grupo tratado em relação ao grupo controle, sugerindo que a inflamação pode já ter regredido no grupo tratado. No entanto, são importantes estudos complementares para determinar a validade da técnica além de isolamento de componente(s) da planta responsável pela influência positiva no processo de reparação de tecidos.

\section{REFERÊNCIAS}

AZEVEDO-MELEIRO, C.H.; RODRIGUEZ-AMAYA, D.B. Confirmation of the identity of the carotenoids of tropical fruits by HPLC-DAD and HPLC-MS. J. Food Compos. Analysis. v.17, n.3/4, p.385-396, 2004.

BATISTA, J. S. et al. Avaliação da atividade cicatrizante do óleo de pequi (Caryocar coriaceum wittm) em feridas cutâneas produzidas experimentalmente em ratos. Arquivo do Instituto Biológico, v. 77, n. 3, p. 441-447, 2010.

CARDOSO, C.R. et al. Influence of topical administration of n-3 and n- 6 essential and n-9 nonessential fatty acids on the healing of cutaneous wounds. Wound Repair and Regeneration, v.12, p.235-243, 2004.

COELHO, N.P.M.F. et al . Cenostigma macrophyllum Tul. on the healing of skin wounds in rats with Diabetes mellitus. Acta Cirurgica Brasileira v. 28, n. 8, p. 594600, ago. 2013.

COTRAN, R.S. et al. Robbins patologia funcional e estrutural. 6.ed. Rio de Janeiro: Guanabara Koogan, 2009.

CRODA DO BRASIL. Crodamazon Pequi. Campinas: Croda, 2002. 2p. [Catálogo].

FALEIRO, F. G. et al. Simpósio nacional sobre o cerrado e o simpósio internacional sobre savanas. In: FALEIRO, F. G.; FARIAS-NETO, A. L. (Ed.). Savanas: desafios e estratégias para o equilíbrio entre sociedade, agronegócio e recursos naturais. Planaltina: Embrapa Cerrados, 2008. p. 32-46.

HATANAKA, E.; CURI, R. Fatty acids and wound healing: a review. Revista Brasileira de Farmácia, v. 88 , n. 2, p. 53-58, 2007.

LIMA, A. et al. Composição química e compostos bioativos presentes na polpa e na amêndoa do pequi (Caryocar brasiliense, Camb.). Revista Brasileira de Fruticultura, v. 29, n. 3, p. 695-698, 2007.

LIMA, A. Ouro do Cerrado. Revista Minas faz Ciência, n. 27, p. 38-41, 2006.

MAIA-FILHO, A. L. M. et al. Efeito do gel da babosa (Aloe barbadensis Mill.) associado ao ultrassom em processo inflamatório agudo. Revista Brasileira de plantas Medicinais, v. 13, n. 2, 2011.

MANDELBAUM, S.H. et al. Cicatrisation: current and auxiliary resources-Part 1. Anais Brasileiros de Dermatologia, v.78, n.4, p.393-410, 2003.

MARTINS, M. et al . Ação anti-inflamatória da fração lipídica do Ovis aries associado ao ultrassom terapêutico em modelo experimental de tendinite em ratos (Rattus norvegicus). Revista Brasileira de Fisioterapia, , v. 15 , n. 4, ago. p. 297-302, 2011. MASSONE, F. Anestesiologia veterinária. 4.ed. Rio de Janeiro: Guanabara Koogan, 2003.

MATOS, F.J.A. Plantas medicinais: guia de seleção e emprego de plantas usadas em fitoterapia no Nordeste do Brasil. 3. ed. Fortaleza: Imprensa Universitária, 2007.

MENDONCA, R.J.; COUTINHO-NETTO, J. Aspectos celulares da cicatrização. Anais Brasileiros de Dermatologia, , v. 84, n. 3, pp. 257-262 2009.

PAULA JUNIOR, W. et al. Leishmanicidal, antibacterial, and antioxidant activities of Caryocar brasiliense Cambess leaves hydroethanolic extract. Revista Brasileira de Farmacognosia, v.16, suppl., p.625630, 2006.

REIS, M. A., TEIXEIRA, V. P. A. Processos Patológicos Gerais - A Regeneração e a Reparação. Faculdade de Medicina do Triângulo Mineiro. Disciplina de Patologia Geral. Uberada/MG, 2004.

ROBBINS S.L, COTRAN R.S. Patologia - Bases Patológicas das Doenças. 7. Ed, Rio de Janeiro: Elservier, 2005.

VIEIRA, A.P. et al. Ação dos flavonóides na cicatrização por segunda intenção em feridas limpas induzidas cirurgicamente em ratos Wistar. Semina. Ciências Biológicas e da Saúde, v. 29, n. 1, p. 65-74, 2008. 